\title{
El Defensor del Pueblo Europeo y el Código Europeo de Buena Conducta Administrativa
}

\author{
Carmen M aría Ávila Rodríguez \\ Ayudante de Derecho Administrativo \\ Universidad de Málaga
}

SUMARIO: I. LA CREACIÓN DEL DEFENSOR DEL PUEBLO EUROPEO. 1. La naturaleza jurídica del O mbudsman y su elección por el Parlamento europeo. 2. La misión que tiene encomendada. 3. El procedimiento de investigación. 3.1. El inicio por reclamación y el inicio de oficio. 3.2. La investigación. 3.3.La conclusión del Procedimiento. 3.4. Los informes. Su contenido y su tramitación. II. EL CÓDIGO EUROPEO DE BUENA CONDUCTA ADMINISTRATIVA.

\section{LA CREACIÓN DEL DEFENSOR DEL PUEBLO EUROPEO}

El nacimiento de la institución del Defensor del Pueblo Europeo se debe al Tratado de Maastricht. Entre el conjunto de derechos que se reconocen en los artículos 8 a $8 \mathrm{E}$ se encuentra el derecho a dirigirse a un Defensor del Pueblo nombrado por el Parlamento, pero éste reconocimiento de 1992 ya llevaba una lenta andadura, pues en enero de 1978, a propuesta del grupo parlamentario conservador, se presentó al Parlamento europeo una proposición para que se crease un grupo de trabajo que estudiase la posible creación de un O mbudsman parlamentario. Un año después el Parlamento Europeo apostaba por la instauración de un Defensor europeo en la "Resolución 140/ 153 concerniente a la designación por el Parlamento Europeo de un O mbudsman para las Comunidades Europeas", pero tras las primeras elecciones celebradas por sufragio universal, la Cámara adoptó un cambio en su posición reconociendo y reforzando el derecho de los ciudadanos a presentar peticiones ante el Parlamento, iniciándose para ello los trabajos para configurar a la Comisión de Peticiones como órgano de control del Parlamento sobre la Comisión y, en consecuencia, relegándose la creación del O mbudsman ${ }^{1}$.

1 Vid. GARCÍA VICENTE, F. "Instrumentos supranacionales reguladores de figuras defensoriales (Unión Europea, Consejo de Europa eInstitutos Especializados), XVI Jornadas de Coordinación del Defensor del Pueblo, 12 y 13 de noviembre de 2001, Madrid. Págs. 25-60. 
La siguiente propuesta de creación se remonta a 1984 cuando el Consejo de Fotainebleau, constatado el alejamiento del ciudadano al proyecto de construcción europeo, constituye el Comité Adonnino encargándole examinar las posibles medidas, todas ellas con la característica de no ser económicas, que pudieran tomarse para acercar la Comunidad a los ciudadanos. Este Comité presentó la primera propuesta sobre la creación del Defensor Europeo pero no prosperó por la falta de entusiasmo del Parlamento Europeo al entender que con esta institución se repetía el derecho de petición.

Más adelante en 1990 el Reino de España en 1990 expuso la idea de la ciudadanía a través de una carta del Presidente del Gobierno dirigida al resto de miembros del Consejo Europeo de Roma. En esta iniciativa se incluía también la propuesta de la creación de un Defensor del Pueblo Europeo para garantizar los derechos que irían adheridos a la condición de ciudadano. El texto español concebía al Defensor en el ámbito de la ciudadanía y proponía la existencia de una especie de mediador comunitario en cada Estado miembro que, eventualmente podía añadirse a los Defensores nacionales ya existentes. El Consejo se mostró favorable a la propuesta española y llegó incluso a mencionar entre las instituciones defensoras de los derechos que compondrían la ciudadanía al O mbudsman.

En 1991 se formalizan dos propuestas, una de la Comisión y otra del Gobierno danés. La Comisión proponía que cada Estado miembro debía adoptar, al menos, una instancia nacional que pudiera tomar la forma de O mbudsman, a la que los ciudadanos de la U nión podrán acudir para la defensa de los derechos derivados del Tratado, para asistirle ante las autoridades administrativas de la U nión y de los Estados miembros, así como para hacer valer esos derechos ante las ins tancias judiciales en el lugar y sitio oportuno a favor de los interesados. De esta propuesta hay que destacar, especialmente dos datos: en primer lugar, incluía la instauración de un Defensor nacional en aquellos países que carecieran de uno o de una institución equivalente para que los ciudadanos pudieran dirigirse a ellos; y en segundo lugar, atribuía a estas instituciones la posibilidad de defender directamente los derechos de la ciudadanía ante las autoridades judiciales, derecho del que carecen la mayoría de los 0 mbudsman nacionales, salvo en algunos casos para la defensa de los derechos fundamentales y frente a los Tribunales de orden constitucional, como el caso español. El gobierno danés presentó la propuesta que finalmente se tuvo en cuenta. El espíritu de la idea danesa situaba al Defensor vinculado al Parlamento pretendiendo reemplazar la Comisión de Peticiones, pero a este respecto la Conferencia intergubernamental se orientó en seguida hacía la inclusión en el Tratado tanto del derecho de petición, artículo 8D primer párrafo, como del mediador, artículo 8D segundo párrafo. 
El régimen jurídico del Defensor del Pueblo de la Unión Europea viene establecido, en primer lugar, en los Tratados Constitutivos: art. 195 del Tratado Constitutivo de la Comunidad Europea (antiguo artículo 138 E) , artículo 20 $\mathrm{D}$ del Tratado Constitutivo de la Comunidad Europea del Carbón y del Acero y art. $107 \mathrm{D}$ del Tratado Constitutivo de la Comunidad Europea de la Energía Atómica. En segundo lugar, estas disposiciones generales encuentran su desarrollo en el Estatuto del Defensor del Pueblo aprobado por el Parlamento Europeo en Decisión de 9 de marzo de $1994^{2}$ y la Decisión de 16 de octubre de 1997 del Defensor del Pueblo Europeo por la que se adoptan medidas de aplicación modificada por la Decisión de 8 de julio de 2002 y modificada, de nuevo, por la Decisión del Defensor del Pueblo de 5 de abril de 2004. ${ }^{3}$

\section{La naturaleza jurídica del 0 mbudsman y su elección por el Parlamento eu- ropeo}

El Defensor del Pueblo Europeo tiene una clara vinculación con el Parlamento Europeo, no sólo por su nombramiento parlamentario de clara influencia sueca, y las relaciones constantes, basadas en la recíproca confianza, que tiene con él a través de la remisión de informes especiales y del informe anual sobre los resultados de las investigaciones, así como la posibilidad que tiene el Parlamento de solicitar al Tribunal la destitución del Defensor, sino también porque la duración de su mandato coincide con el periodo de la legislatura del Parlamento, dato que deja ver que la independencia en su funcionamiento es relativamente más segura con el ejecutivo comunitario que con el Parlamento 4 .

Aunque ni en el artículo $138 \mathrm{E}$ ni en su Estatuto Jurídico se contenga la expresión de Comisionado Parlamentario para definir su naturaleza jurídica,

\footnotetext{
2 Decisión del Parlamento Europeo sobre el Estatuto del Defensor del Pueblo y sobre las condiciones generales del ejercicio de sus funciones, DOCE, L, 113, 4 de mayo de 1994, págs. 15-18.

${ }^{3}$ La normativa reguladora del Defensor del Pueblo Europeo es el resultado de una disposición normativa especial cuya formulación se llevó a cabo por Decisión del Parlamento previa aprobación conjunta del Parlamento y el Consejo. Es también calificada como una norma particular, por ser una norma jurídica de derecho derivado no exclusivamente organizativa, ya que implica derechos de los ciudadanos europeos, de aplicación directa y de carácter general.

${ }^{4}$ En relación al principio de independencia ver el Artículo 9 apartados 1 y 2 y el artículo 10 del Estatuto del Defensor del Pueblo. Otro vínculo que merman la independencia del Ombudsman frente al Parlamento además de los citados es que tenga su sede en la misma del Parlamento Europeo (art. 13).
} 
estamos ante una institución de este tipo. El procedimiento de designación del Defensor del Pueblo Europeo se encuentra regulado en el Reglamento interno del Parlamento Europeo ${ }^{5}$ y en él podemos distinguir cuatro fases: La presentación de candidaturas, el examen de idoneidad, la votación del Parlamento y el juramento ante el Tribunal de Justicia de las Comunidades Europeas.

La presentación de las candidaturas se realiza tras la convocatoria que el Presidente del Parlamento lleva a cabo al principio de cada legislatura, publicándola en el DOUE. Se necesita del apoyo de 29 diputados, como mínimo, de, al menos, dos Estados miembros para que cada candidatura sea tenida en cuenta, siendo necesario que vayan acompañadas de todos los justificantes necesarios para establecer con seguridad que el candidato reúne las condiciones enunciadas en el Estatuto del Defensor. Cerrado el plazo de presentación, las candidaturas se transmiten a la comisión competente, que no es otra que la Comisión de Peticiones, para iniciar el trámite de la audiencia a los candidatos que tiene por objeto realizar el examen de idoneidad. La audiencia, que será pública a todos los diputados, consta de dos partes, una primera más breve en la que el candidato procede a su presentación, y otra más extensa en la que los parlamentarios hacen preguntas. Realizadas las audiencias, la lista al fabética de las candidaturas admitidas a trámite se someten a la votación del Parlamento realizada mediante voto secreto y por mayoría de los votos emitidos; pero antes de declarar abierta la votación, para dotar de mayor representatibidad y legitimidad al candidato que salga finalmente elegido, el Presidente comprueba la existencia de la mitad como mínimo de los diputados que integran el Parlamento. Si, al finalizar las dos primeras votaciones, no resulta elegido ningún candidato, únicamente podrán mantenerse los dos candidatos que hayan obtenido el mayor número de votos en la segunda votación. En todos los casos de empate de votos, se considera vencedor, al candidato de más edad.

El candidato nombrado es llamado inmediatamente a prestar juramento o promesa ante el Tribunal de Justicia, y una vez prestado, ejercerá el cargo hasta la entrada en funciones de su sucesor, excepto en el caso de cese por fallecimiento o destitución ${ }^{6}$.

\footnotetext{
${ }^{5}$ Capítulo XX, artículo 159 cuya rúbrica lleva por nombre "Nombramiento del Defensor del Pueblo" del Reglamento Interno del Parlamento Europeo y artículo 6.1 y 9.2 de la Decisión del Parlamento Europeo sobre el Estatuto del Defensor del Pueblo y sobre las condiciones Generales del ejercicio de sus funciones.

${ }^{6}$ El finlandés Jacob Södermann, fue elegido primer titular de la institución en julio de 1995, y fue renovado en su mandato el 27 de octubre de 1999 hasta el año 2003 en el que ha sido relevado por el griego P. Nikiforos Diamandouros.
} 


\section{La misión que tiene encomendada}

El O mbudsman está facultado para recibir reclamaciones relativas a casos de mala administración en la acción de las instituciones u órganos comunitarios, con exclusión del Tribunal de Justicia y del Tribunal de Primera Instancia en el ejercicio de sus funciones jurisdiccionales ${ }^{7}$. A pesar de la complejidad de definir qué se entiende por mala administración, este concepto es genéricamente identificable con el agravio administrativo o con la incorrección administrativa no susceptible de recurso ${ }^{8}$. Es obvio que cuando hablamos de mala administración no es simplemente de ilegalidad ya que entonces bastaría con el control del Tribunal de Justicia, la razón de ser del Defensor es la existencia de un ámbito intermedio entre lo estrictamente ilegal y lo que sin serlo, sin ser justiciable, se configura como una actuación que no se realiza de conformidad con las normas o principios a los que debe obligatoriamente atenerse, tal y como ha manifestado el Defensor del Pueblo Europeo en el Informe anual de $1997^{9}$.

El propio Defensor del Pueblo en un folleto editado en 1996, y más adelante en el Informe anual de 1997, arrojó luz sobre este concepto tan oscuro e impreciso, bajo la fórmula de una enumeración ejemplificativa en la que incluía: irregularidades administrativas, omisiones administrativas, abusos de poder, negligencias, procedimientos ilícitos, favoritismos, casos de disfuncionalidad o incompetencia, discriminaciones, retrasos injustificados, falta de información o negativa a proporcionar información. U na perspectiva que no se puede olvidar y sobre la que hay que proyectar este concepto de mala administración es el servicio público, en éste se produce mala administración cuando la institución o cualquier otro organismo comunitario encargado de una

\footnotetext{
${ }^{7}$ Artículo 138 E del TUE, artículo 43 de la Carta de los Derechos Fundamentales de la U nión Europea proclamada en la cumbre de Niza en diciembre de 2000, artículo 2.1 y artículo 3.1 de la Decisión del Parlamento Europeo sobre el Estatuto del Defensor del Pueblo y sobre las condiciones generales del ejercicio de sus funciones ( 9 de marzo de 1994).
}

${ }^{8}$ En su Informe anual de 1997, en respuesta a un requerimiento del Parlamento Europeo para que se incluyera una definición clara del concepto de mala administración, el Defensor del Pueblo concluyó que: "Se produce mala administración cuando un organismo público no obra de conformidad con las normas o principios a los que debe obligatoriamente aten erse". En 1998, el Parlamento Europeo aprobó una resolución que aceptaba esta definición. A lo largo de 1999, el Defensor del Pueblo y la Comisión mantuvieron un intercambio de correspondencia del que se deduce que la Comisión también estaba de acuerdo con esta definición. Ver Informe de 2005, pág. 39.

9 Ver Informe 1997, págs. 24 a 26. 
misión de servicio público no ha funcionado de acuerdo con esa misión. Cuando se habla de mala administración no se trata de una cuestión de pura y simple corrección jurídica, sino que la actuación jurídica administrativa es preciso completarla con la reacción del ciudadano, con su conciencia de agravio administrativo.

\section{El procedimiento de investigación}

\subsection{El inicio por reclamación y el inicio de oficio}

Cualquier ciudadano, entendiendo por tal toda persona física o jurídica, que conozca de un caso de mala administración puede presentar una reclamación ante el Defensor del Pueblo Europeo. Para poder presentar la reclamación no se exige ningún interés legítimo ni particular. Pudiéndose dar por tanto dos intenciones en la presentación de reclamaciones: aquel ciudadano que afectado de un caso de mala administración persigue la actuación del 0 mbudsman para ser resarcido en su derecho o interés y aquel ciudadano que sin tener un interés concreto y personal conoce de un caso de mala administración y pone en marcha la actuación del O mbudsman para defender el interés general de una Administración buena y adecuada.

El Estatuto del Defensor del Pueblo Europeo no reconoce expresamente la posibilidad de presentar reclamaciones a los parlamentarios de motu propio, sino a instancias y como mediadores entre una persona física o jurídica y el Defensor del Pueblo Europeo. Este sistema está influenciado por la institución del Mèdiateur y del Parliamentary Commissioner of Administration en los cuales se ha renunciado a un acceso directo del ciudadano a los O mbudsman a través de la obligatoria intermediación de un parlamentario. Esta influencia ha de ser correctamente interpretada porque en el caso del Defensor del Pueblo Europeo no existe una obligación sino una opción alternativa respecto al acceso directo ${ }^{10}$. Por tanto la doble posibilidad de presentar la queja por si 0 a través de un parlamentario no es un reconocimiento expreso de la legitimidad de los parlamentarios para formular reclamaciones sino una ventaja que favorece al ciudadano para relacionarse con el Defensor Europeo ampliando sus formas para acceder a él.

10 Vid. PELLÓN RIVERO, R. “EI Defensor del Pueblo. Legislación española y Derecho Comparado", Servicio Central de Publicaciones de la Presidencia del Gobierno. Madrid, 1982 y CARMONA y CHOUSSAT, J. F. "El Defensor del Pueblo Europeo". Instituto Nacional de Administración Pública, Madrid, 2000. 
La presentación de las reclamaciones se puede formular en cualquiera de las lenguas oficiales de la Unión Europea, si se utilizan otras lenguas el Defensor del Pueblo Europeo no está obligado. La lengua en la que se presente la reclamación es la aplicada al procedimiento, sin perjuicio de que la correspondencia con las autoridades de los Estados miembros se mantendrá en la lengua oficial del Estado del que se trate. En la reclamación tiene además que constar el objeto de la misma que en todo caso ha de ser una situación de mala administración que se hayan producido por las instituciones y los órganos comunitarios, con exclusión del Tribunal de Justicia y del Tribunal de primera instancia. También ha de quedar patente e identificada la persona que formula la reclamación.

Si la reclamación es formulada por una persona jurídica deben constar el nombre, el Estado miembro en que tengan registradas sus oficinas y la dirección de sus oficinas. La razón por la que existen mayores exigencias de admisibilidad para la formulación de reclamaciones de personas jurídicas se asienta además de asegurar que el domicilio social radique en el territorio de la Unión, en el hecho mismo del fundamento de existencia del propio Defensor Europeo, es decir, en su misión de acercar el ciudadano a la U nión no tanto a través de sus organizaciones sino individualmente como tales, de ahí que los criterios de admisibilidad de reclamaciones individuales sean flexibles y no se fundamenten en un enfoque excesivamente técnico y legalista.

El Defensor del Pueblo Europeo puede actuar de oficio pues su normativa reguladora le otorga competencia para proceder a todas las investigaciones que considere necesarias para aclarar todo posible caso de mala administración en la actuación de la Administración u órganos comunitarios por iniciativa propia ${ }^{11}$. Para ello dispone de las mismas facultades de investigación y sigue el mismo procedimiento que para las investigaciones abiertas a instancia de parte. No obstante, el Defensor del Pueblo Europeo no debe abusar de su actuación de oficio al ser el fundamento de su existencia hacer oír la voz de los débiles, por tanto solo deberá actuar de oficio en aquellos casos en los que tras detectar y constatar una necesidad ciudadana, ésta aún no haya sido manifestada por los propios ciudadanos ${ }^{12}$.

${ }^{11}$ Artículo 138 E del TUE, artículo 3.1 del Estatuto del Defensor del Pueblo y artículo 9 de la Decisión de 8 de julio del Defensor del Pueblo por la que se adoptan normas de decisión.

12 Vid. CARMO NA y CHOUSSAT, J.F., "El Defensor del Pueblo Europeo" INAP, Ministerio de Administraciones Públicas. Madrid, 2000, cit. pag. 264. 
El Estatuto del Defensor del Pueblo Europeo establece un límite temporal para poder presentar la reclamación que se extiende a dos años contados desde que el promotor de la misma tuvo conocimiento de los hechos que la motivaron, siendo necesario que previamente se hayan hecho adecuadas gestiones administrativas ante las instituciones u órganos de que se trate. Parece ser por tanto que con este requisito se está persiguiendo el agotamiento de la vía administrativa para dar al órgano o a la institución la posibilidad de revalorar y corregir con sus propios mecanismos internos su conducta o actuación.

Una vez que el 0 mbudsman recibe la reclamación tiene la obligación de informar sin demora al ciudadano sobre el curso dado a la misma y, en el caso de ser rechazada, el Defensor puede aconsejar que el reclamante se dirija a otra autoridad con competencia en el caso planteado. En el acuse de recibo se tiene que indicar el número del registro con el que ha sido identificada en su recepción la queja y la identificación del jurista que ha sido asignado a su asunto.

Las reclamaciones pueden ser inadmitidas si aún estando fundadas en casos de "mala administración", no se refiere a una institución o un órgano comunitario. I gualmente se inadmiten las reclamaciones que versen sobre el Tribunal de Justicia y el Tribunal de Primera Instancia y también aquéllas que aún estando dentro de la competencia del 0 mbudsman, estén siendo o hayan sido sometidas a los Tribunales ${ }^{13}$.

\subsection{La investigación}

El Defensor del Pueblo Europeo procede a todas las investigaciones que considere necesarias para aclarar todo posible el caso de mala administración. Para ello se suceden una serie de comunicaciones entre el Ombudsman y la institución u órgano afectado y entre el O mbudsman y el reclamante. Con este proceder el ejercicio de la actividad investigadora se concibe como una ac-

\footnotetext{
13 Sobre esta cuestión consultar el artículo 1.3 y el artículo 3.7 del Estatuto del Defensor del Pueblo Europeo y el artículo 10.3 de la Decisión del Defensor del Pueblo Europeo de 8 de julio 2002 por la que adopta medidas de ejecución. En el Estatuto se prevé la circunstancia del sometimiento del asunto a los Tribunales como una causa de inadmisión, es decir, antes de que el Defensor entre en el estudio de la reclamación. Pero la Decisión va más allá porque prevé la circunstancia de que siendo la reclamación objeto de estudio de los servicios del Defensor e incluso habiéndose obtenido resultados de las investigaciones a las que se haya podido proceder, se incoe, antes de concluir definitivamente las actuaciones el Defensor, un procedimiento jurisdiccional relativo a los hechos de la reclamación, obligándole a archivar todo lo desarrollado al efecto.
} 
tividad de recopilación de información en la que se cuenta con el órgano o institución controlada con la principal finalidad de lograr la colaboración administrativa porque en aras de la actividad de control resulta mucho más efectivo contar con la aceptación o al menos la comprensión de los controlados, de ahí que la Decisión de 8 de julio de 2002 exija el previo aviso para que el Defensor del Pueblo Europeo pueda personarse directamente en la oficina administrativa afectada, llevando a cabo sus investigaciones in situ .

Una vez admitida la reclamación, el Defensor del Pueblo Europeo informa a la institución u órgano afectado sin que ello se traduzca en una obligación para el órgano o la institución informada en el sentido de emitir un informe, puesto que en el Estatuto del Defensor del Pueblo se recoge solo la posibilidad de comunicar cualquier información útill14. Ahora bien, este carácter potestativo de la comunicación de información útil se convierte en obligatorio cuando la información es exigida por el Defensor del Pueblo Europeo. Entonces la institución u órgano afectado está obligado a remitirle la información solicitada y darle acceso a la documentación relativa al caso, obligación solo excepcionada por razón de secreto o confidencialidad debidamente justificada $^{15}$. Las previsiones contenidas en la Decisión del Defensor del Pueblo Europeo de 8 de julio 2002 son contradictorias con lo explicado anteriormente porque si bien en el Estatuto parece deducirse que la emisión del informe por parte de la institución informada de la reclamación es potestativo, la Decisión establece que una vez transmitida a la institución afectada una copia de la reclamación, se le solicita que emita un dictamen dentro de un plazo determinado por el Defensor que no ha de exceder de tres meses. La trascendencia de este dictamen radica en que una vez recibido por el Defensor, salvo que lo considere inoportuno, lo remite al ciudadano que formuló la reclamación para que presente observaciones en el plazo de un mes. La reclamación, el dictamen y las observaciones realizadas por el ciudadano son el objeto de examen del Defensor del Pueblo para decidir si archiva el asunto mediante decisión motivada, o si prosigue su investigación, informando en consecuencia al ciudadano y a la institución afectada ${ }^{16}$.

${ }^{14}$ Artículo 3.1 del Estatuto del Defensor del Pueblo Europeo.

15 Para ver esta cuestión del secreto comunitario consultar CARMONA y CH OUSSAT, J.F., "EI Defensor del Pueblo Europeo"..., página 265 a 271.

${ }^{16}$ Artículo 4 de la Decisión 
Para realizar las labores de investigación, el O mbudsman cuenta con una serie de garantías así debe poder contar con todos los elementos necesarios para el ejercicio de sus funciones y para ello las instituciones y órganos comunitarios tienen el deber de facilitarles la información que solicite, a no ser que se opongan a ello motivos de secreto debidamente justificados, y sin perjuicio de la obligación que incumbe al Defensor de no divulgar dicha información. Además de esta obligación dirigida a las instituciones y órganos comunitarios, las autoridades de los Estados miembros también deben facilitar toda la información necesaria, a no ser que dicha información esté amparada por disposiciones legales o reglamentarias relativas al carácter secreto, o bien por cualquier otra disposición que impida su transmisión. No obstante, la calificación de secreto de los documentos solicitados el Estado miembro de que se trate podrá permitir al Defensor el acceso a dicha información siempre y cuando se comprometa a no divulgar el contenido de la misma. El conducto para facilitar la información solicitada son las Representaciones Permanentes de los Estad os miembros ante las Comunidades Europeas.

Si el O mbudsman en su investigación tiene conocimiento de hechos presuntamente delictivos debe informar inmediatamente a las autoridades nacionales competentes a través de las Representaciones Permanentes de los Estados miembros ante las Comunidades europeas así como, en su caso, a la institución comunitaria a que pertenezca el funcionario o el agente afectado. I gualmente podrá informar a una institución u órgano comunitario de los hechos que, a su entender, pudieran justificar la apertura de un procedimiento disciplinario ${ }^{17}$.

\subsection{La conclusión del Procedimiento}

Una vez que el Defensor del Pueblo Europeo ha constatado en su actuación investigadora un caso de mala administración, puede llevar a cabo funciones de mediador cooperando, en la medida de lo posible, con la Institución afectada para encontrar una solución amistosa que suprima el caso de mala Administración y dé satisfacción al ciudadano. Si el Defensor estima que una cooperación de este tipo ha tenido existo, archivará el asunto mediante una decisión motivada, informado de su decisión al ciudadano y a la institución afectada. Si la eliminación del caso de mala Administración no se ha producido puede optar entre archivar el asunto mediante decisión motivada conteniendo algún comentario crítico con la posterior comunicación obligada al

${ }^{17}$ Artículo 4.2 del Estatuto y artículo 10.4 de la Decisión de 8 de julio 2002. 
ciudadano, o puede elaborar un informe con un proyecto de recomendación que también comunicará al ciudadano ${ }^{18}$. El comentario crítico se formula si considera que ha dejado de ser posible que la institución afectada suprima el caso de mala administración y cuando éste no haya tenido consecuencias generales. La elaboración de un informe con proyectos de recomendación dirigidos a la institución afectada procede si considera que es posible que la institución afectada suprima el caso de mala administración o si éste tiene consecuencias generales ${ }^{19}$.

Ante esta situación, la institución interesada remite al Defensor del Pueblo un dictamen circunstanciado en el plazo de tres meses, pudiendo suponer éste la aceptación de la decisión del Defensor en el que deberá detallar las medidas adoptadas con vistas a la ejecución de las recomendaciones. Si por el contrario el Defensor no considera que el dictamen circunstanciado es satisfactorio, elabora un informe sobre el caso de mala administración en el que puede incluir recomendaciones siendo elaborado en forma de informe especial dirigido al Parlamento Europeo.

\subsection{Los informes. Su contenido y su tramitación}

Podemos distinguir dos tipos de informes: El especial yel anual. El informe especial es el que abarca el tratamiento individualizado y separado de las reclamaciones y es elevado al Parlamento cuando el O mbudsman concluye la investigación de una reclamación constatando un caso de mala administración, y tras haberse dirigido a la institución u órgano comunitario afectado formulando un proyecto de recomendación y habiendo recibido el informe motivado de éstos, estima que dicho informe no es satisfactorio. Los informes especiales pueden contener recomendaciones al margen de poner en conocimiento al Parlamento del caso de mala administración.

El informe anual es aquel que al final de cada periodo anual de sesiones presenta al Parlamento Europeo y en los que se rinden cuentas del conjunto de su actividad y especialmente del resultado de sus investigaciones ${ }^{20}$.

18 Ejemplos de esta actividad mediadora los encontramos en el Informe de la gestión realizada durante el año 2000 en la página 135; en el Informe de la gestión realizada durante el año 2002 en la página 84 y en el Informe de la gestión realizada durante el año 2003 en la página 5.

${ }^{19}$ Artículo 7 y artículo 8 respectivamente de la Decisión de 8 de julio 2002.

${ }^{20}$ Artículo 3.8 del Estatuto del Defensor del Pueblo Europeo. Este artículo se ha limitado a reproducir el artículo $138 \mathrm{E}$ del TUE sin añadir nada nuevo ni concretar el plazo de presentación ni delimitar su contenido positiva o negativamente 
El Informe anual se presenta ante la Comisión de Peticiones y ésta elabora un informe que se someterá a debate del Pleno. En el BOUE se publican los anuncios sobre la aprobación de los informes anuales y especiales y los modos en los que los interesados pueden tener acceso al texto completo de los documentos. En la medida de lo posible ambos informes se elaboran en todas las lenguas oficiales ${ }^{21}$.

\section{EL CÓdIGO EUROPEO DE BUENA CONDUCTA ADMINISTRA- TIVA}

Si hay que destacar un aspecto de la labor desarrollada por el Defensor del Pueblo Europeo desde su instauración es el esfuerzo que viene desarroIlando para implantar en las Instituciones comunitarias un Código de Buena Conducta Administrativa. Resultado de ello es la aprobación el 6 de septiembre de 2001, por el Parlamento europeo de un Código de Buena Conducta Administrativa dirigido a las instituciones y órganos de la U nión Europea, cuyos contenidos deben ser respetados por esta Administración y sus funcionarios en las relaciones con los ciudadanos.

La idea de un Código similar había sido propuesta en 1998 por el parlamentario europeo, Sr. Roy Perry. El Defensor del Pueblo Europeo redactó un proyecto de texto, siguiendo una investigación de oficio que tenía por objeto determinar si los órganos e instituciones de la Comunidad contaban con un código de buena conducta administrativa en las relaciones de los funcionarios con el público, y si dicho código era accesible al público. El Defensor del Pueblo Europeo dirigió proyectos de recomendación a la Comisión y al Parlamento y al Consejo respectivamente, el 28 y 29 de julio de 1999 y el 13 de septiembre de ese mismo año dirigió otros proyectos similares a otras instituciones, órganos y agencias descentralizadas. El Defensor del Pueblo Europeo adjuntó a sus proyectos de recomendación un código de buena conducta administrativa elaborado por su Secretaría y que contenía, en una lista de 28 artículos, como veremos, las disposiciones relativas tanto a los principios sustanciales y de procedimiento como al buen funcionamiento de la administración. El Defensor del Pueblo declaró que las instituciones y órganos podrían utilizar este proyecto de código como guía para redactar sus propios códigos.

${ }^{21}$ Artículo 179 del Reglamento del Parlamento Europeo, artículo 16.1 y artículo 15.5 de la Decisión de 8 de julio 2002. 
En abril de 2000, después de analizar a fondo las opiniones recibidas de las distintas instituciones y órganos sobre sus proyectos de recomendación, el Defensor del Pueblo presentó un informe especial al Parlamento Europeo formulando la siguiente recomendación: "Con el objeto dellegar a establecer unas normas de buena conducta administrativa aplicables por igual a todas las instituciones y órganos comunitarios en sus relaciones con el público, el Defensor del Pueblo recomienda la promulgación de una normativa administrativa europea, aplicable a todas las instituciones y órganos comunitarios. Dicha normativa podría adoptar la forma de Re glamento". El Defensor adjuntó su proyecto de Código al informe especial22.

El 27 de junio de 2001, la Comisión de Peticiones del Parlamento Europeo aprobó un informe redactado por el eurodiputado Roy Perry que apoyaba el informe especial del Defensor del Pueblo y el 6 de septiembre de ese mismo año, el Parlamento Europeo aprobó una Resolución en la que invitaba a la Comisión Europea a presentar una propuesta de Reglamento que incluyera el Código de Buena Conducta Administrativa, de manera que la incorporación del texto a un Reglamento pondría de relieve la naturaleza obligatoria de la que ahorra carecen sus normas y sus principios ${ }^{23}$.

La necesidad de la aprobación de este Reglamento es notoria puesto que se reconocen los derechos de los ciudadanos frente a la Administración comunitaria y los principios y pautas de actuación de la Administración en su proceder ordinario y cotidiano, más aún cuando La Carta de Derechos Fundamentales de la Unión Europea, proclamada en la cumbre de Niza en diciembre de 2000, incluye como derechos fundamentales de los ciudadanos el derecho a una buena administración y el derecho a someter al Defensor del Pueblo de la Unión los casos de mala administración. El Código pretende concretar en la práctica lo que significa el derecho a una buena administración establecido en la Carta.

El Código está formado por 27 artículos y es aplicable, en las relaciones con el público, a todos los funcionarios y otros agentes para los que rigen el

\footnotetext{
22 Informe especial del Defensor del Pueblo Europeo al Parlamento Europeo relativo a su investigación por iniciativa propia sobre la existencia y el acceso público a un Código de buena conducta administrativa en las instituciones y órganos comunitarios (OI/ 1/ 98/ OV) 11.04.2000.

${ }^{23}$ Informe del Defensor del Pueblo Europeo de 2002, pag. 204. El procedimiento para la adopción de un Reglamento requerirá una iniciativa formal de la Comisión de Asuntos Jurídicos del Parlamento Europeo, la elaboración de la propuesta por parte de la Comisión sobre la que debería tomar un acuerdo unánime el Consejo.
} 
Estatuto y el régimen aplicable a otros agentes de las Comunidades Europeas, así será de aplicación a las personas contratadas bajo la modalidad de contratos de Derecho privado, expertos de administraciones nacionales en comisión de servicios y becarios. No será por tanto aplicable a las relaciones entre la Institución y sus funcionarios ya que éstas se encuentran regidas por el Estatuto.

Tal y como establece el Código, en el ejercicio de las funciones del personal de la Administración comunitaria deben prevalecer los valores fundamentales de legitimidad, no discriminación, proporcionalidad, imparcialidad, independencia, objetividad, profesionalidad y justicia, desterrando toda conducta de abuso de poder. Ello exige que se actúe de conformidad con la legislación, velando para que las decisiones que afecten a los derechos o intereses de los ciudadanos estén basadas en la ley²4; exige que se garantice el respeto del principio de igualdad de trato, evitando conductas de discriminación injustificada ${ }^{25}$ y acciones arbitrarias que dispensen un trato preferente ${ }^{26}$; requiere que los poderes se ejerzan únicamente con la finalidad para los que han sido otorgados ${ }^{27}$, adoptándose decisiones justas ${ }^{28}$ que respeten el justo equilibrio entre los intereses individuales y el interés público general ${ }^{29} \mathrm{e}$ implica coherencia en la práctica administrativa respetándose las legítimas y razonables expectativas que los miembros del público tengan a la luz de la actuación administrativa precedente ${ }^{30}$. Todas estas actuaciones deben ir inspiradas por el principio de cortesía que implica que el funcionario sea diligente, correcto, cortés y accesible en sus relaciones con el público ${ }^{31}$.

El Código de Buena Conducta Administrativa exige que en los procedimientos administrativos se asegure que todo ciudadano de la Unión, persona

\footnotetext{
${ }^{24}$ Artículo 4 del Código de Buena Conducta Administrativa.

${ }^{25}$ Artículo 5 del Código de Buena Conducta Administrativa.

${ }^{26}$ Artículo 8 del Código de Buena Conducta Administrativa.

${ }^{27}$ Artículo 7 del Código de Buena Conducta Administrativa.

${ }^{28}$ Artículo 9 y 11 del Código de Buena Conducta Administrativa.

${ }^{29}$ Artículo 6 del Código de Buena Conducta Administrativa.

${ }^{30}$ Artículo 10 del Código de Buena Conducta Administrativa.

${ }^{31}$ Artículo 12 del Código de Buena Conducta Administrativa.
} 
jurídica o Asociación que se dirijan por escrito a una Institución europea en una de las lenguas del Tratado reciba su acuse de recibo y su respuesta en esa misma lengua 32 . El acuse de recibo ha de efectuarse en el plazo de dos semanas indicando el nombre y el número de teléfono del funcionario que se ocupe del asunto, así como del servicio al que dicho funcionario pertenece, excepcionándose esta obligación sólo en los casos en los que las cartas o reclamaciones resulten impertinentes por su número excesivo o su carácter repetitivo o absurdo ${ }^{33}$. I gualmente se reconoce el derecho a subsanar los errores $u$ omisiones que pudieran encontrarse en los escritos y documentos ${ }^{34}$, así como el derecho a la defensa en todos aquellos casos en los que se adopte una decisión que afecte a los derechos o intereses de un particular ${ }^{35}$ incluso procediéndose al derecho de apelación ${ }^{36}$ y de reclamación ante el Defensor del Pueblo Europeo ${ }^{37}$.

El Código de Buena Conducta impone a las Instituciones europeas la obligación de remisión al servicio competente, de las cartas o reclamaciones transmitidas a una Dirección General, a una Dirección o a una Unidad incompetente, notificándolo al autor de éstas indicándole el nombre y el número de teléfono del funcionario al que se ha transmitido el expediente ${ }^{38}$. Igualmente el Código establece la obligación de que las decisiones sean adoptadas en un plazo razonable fijado en un periodo de dos meses y previendo que si un asunto no pudiera ser resuelto en ese tiempo se debe informar al interesado con la mayor brevedad posible ${ }^{39}$. Además de ello, toda decisión que pueda afectar adversamente a los derechos o intereses de una persona privada debe indicar los motivos en los que está basada, exponiendo claramente los hechos pertinentes y el fundamento jurídico de la decisión, evitando de este

\footnotetext{
${ }^{32}$ Artículo 13 del Código de Buena Conducta Administrativa.

${ }^{33}$ Artículo 14 del Código de Buena Conducta Administrativa.

${ }^{34}$ Artículo 15 del Código de Buena Conducta Administrativa.

${ }^{35}$ Artículo 16 del Código de Buena Conducta Administrativa.

${ }^{36}$ Artículo 19 del Código de Buena Conducta Administrativa.

${ }^{37}$ Artículo 26 del Código de Buena Conducta Administrativa.

${ }^{38}$ Artículo 15 del Código de Buena Conducta Administrativa.

${ }^{39}$ Artículo 17 del Código de Buena Conducta Administrativa.
} 
modo la adopción de decisiones basadas en motivos breves o vagos o que no contengan un razonamiento individual ${ }^{40}$. Asimismo se impone la obligación de notificar por escrito a la persona o personas afectadas las decisiones que conciernan a sus derechos o intereses, absteniéndose el funcionario de comunicar la decisión a otras fuentes antes de que la persona o personas afectadas hayan sido informadas ${ }^{41}$. Por último en todo trámite y gestión el funcionario que maneje datos personales referentes a un ciudadano está obligado a respetar la vida privada y la integridad de la persona, de conformidad con las disposiciones normativas relativas a la protección de las personas físicas en lo que respecta al tratamiento de datos personales ${ }^{42}$.

A pesar de los importantes esfuerzos llevados a cabo por la institución del O mbudsman en la elaboración y reconocimiento del Código de Europeo de Buena Conducta Administrativa hay un aspecto susceptible de mejora. En su artículo 27 se establecía la obligación de revisión del Código para que cada Institución europea, una vez transcurrido dos años, examinara su aplicación y presentara un Informe con los resultados de este examen al Defensor del Pueblo Europeo, pues bien, no hay ninguna constancia de esta revisión en los informes del 0 mbudsman. Si consideramos que la publicación a través de los Informes anuales del 0 mbudsman es el cauce idóneo para dar publicidad a los informes de evaluación de la aplicación del Código por las respectivas Instituciones Europeas 0 , al menos, el vehículo adecuado para hacer pública una reseña de los mismos, y ello no se produce, surge la duda de si efectivamente se está cumpliendo con ello.

\footnotetext{
${ }^{40}$ Artículo 18 del Código de Buena Conducta Administrativa.

${ }^{41}$ Artículo 20 del Código de Buena Conducta Administrativa.

42 Artículo 21 del Código de Buena Conducta Administrativa.
} 